https://helda.helsinki.fi

Cortical responses to tactile stimuli in preterm infants

\title{
Leikos, Susanna
}

2020-02

Leikos , S , Tokariev , A , Koolen , N , Nevalainen , P \& Vanhatalo , S 2020 , ' Cortical

responses to tactile stimuli in preterm infants ' , European Journal of Neuroscience , vol. 51 , no. 4 , pp. 1059-1073 . https://doi.org/10.1111/ejn.14613

http://hdl.handle.net/10138/320990

https://doi.org/10.1111/ejn.14613

acceptedVersion

Downloaded from Helda, University of Helsinki institutional repository.

This is an electronic reprint of the original article.

This reprint may differ from the original in pagination and typographic detail.

Please cite the original version. 
MS. SUSANNA LEIKOS (Orcid ID : 0000-0001-5611-0725)

Article type : Research Report

Proposed section: Developmental Neuroscience

\section{Cortical responses to tactile stimuli in preterm infants}

Susanna Leikos ${ }^{1, *}$, Anton Tokariev ${ }^{1}$, Ninah Koolen $^{1}$, Päivi Nevalainen ${ }^{1}$, Sampsa Vanhatalo ${ }^{1}$

${ }^{1}$ Children's Clinical Neurophysiology, BABA Center, Children's Hospital, HUS Medical Imaging Center, Helsinki University Hospital and University of Helsinki, Helsinki, Finland

* Corresponding author

Address correspondence to Susanna Leikos, BABA center (www.babacenter.fi), Department of Clinical Neurophysiology, University of Helsinki, PO Box 281, 00029 HUS, Helsinki, Finland. Email: susanna.leikos@helsinki.fi

Running title: Cortical somatosensory reactions in the preterm

Number of pages: 42

Number of figures: 5

Number of tables: 1

Number of equations: 0

This article has been accepted for publication and undergone full peer review but has not been through the copyediting, typesetting, pagination and proofreading process, which may lead to differences between this version and the Version of Record. Please cite this article as doi: 10.1111/EJN.14613

This article is protected by copyright. All rights reserved 
Number of words in (i) the whole manuscript: 7208, (ii) the Abstract: 234

Keywords: brain monitoring; EEG; somatosensory evoked potentials; intraventricular haemorrhage; neonatal intensive care unit 


\section{Abstract}

The conventional assessment of preterm somatosensory functions using averaged cortical responses to electrical stimulation ignores the characteristic components of preterm somatosensory evoked responses (SERs). Our study aimed to systematically evaluate the occurrence and development of SERs after tactile stimulus in preterm infants. We analysed SERs performed during 45 electroencephalograms (EEGs) from 29 infants at the mean post-menstrual age of 30.7 weeks. Altogether 2,087 SERs were identified visually at single trial level from unfiltered signals capturing also their slowest components. We observed salient SERs with a high amplitude slow component at a high success rate after hand (95\%) and foot (83\%) stimuli. There was a clear developmental change in both the slow wave and the higher frequency components of the SERs. Infants with intraventricular haemorrhage (IVH; eleven infants) had initially normal SERs, but those with bilateral IVH later showed a developmental decrease in the ipsilateral SER occurrence after 30 weeks of post-menstrual age. Our study shows that tactile stimulus applied at bedside elicits salient SERs with a large slow component and an overriding fast oscillation, which are specific to the preterm period. Prior experimental research indicates that such SERs allow studying both subplate and cortical functions. Our present findings further suggest that they might offer a window to the emergence of neurodevelopmental sequalae after major structural brain lesions and, hence, an additional tool for both research and clinical neurophysiological evaluation of infants before term age.

\section{Introduction}

Prematurity remains a significant risk factor for neurodevelopmental sequelae (Saigal \& Doyle, 2008; Mwaniki et al., 2012; Johnson \& Marlow, 2017), and improving early neurological assessment of infants with brain injury remains a key challenge in the development of early interventional strategies (Marlow et al., 2005; Pisani \& Spagnoli, 2016). There is a particular lack of bedside methods that would allow non-invasive and minimally disturbing, yet clinically robust assessment of early brain function in the neonatal intensive care unit (NICU) environment.

Prior studies on term newborns have shown that somatosensory evoked potentials (SEPs) offer an objective bedside measure with high predictive accuracy after birth asphyxia (Willis et al., 1987; Majnemer \& Rosenblatt, 1996; Scalais et al., 1998; Suppiej et al., 2010; Swarte et al., 2012; Kontio et al., 2013; Nevalainen et al., 2017; Nevalainen et al., 2018; Suppiej et al., 2018). The SEPs are conventionally generated by rapidly repeated electrical or tactile stimulation (Hrbek et 
al., 1973; Willis et al., 1984; Laureau \& Marlot, 1990; Karniski et al., 1992; Taylor et al., 1996; Pike \& Marlow, 2000; Smit et al., 2000; Pihko et al., 2004; Nevalainen et al., 2008), and the cortical responses are typically assessed from the first component of an averaged EEG waveform (a.k.a. N1 in neonates) (Desmedt et al., 1976; Willis et al., 1984; Pike et al., 1997; Tombini et al., 2009). However, prior studies on preterm infants have shown that such conventional SEPs have much less information value in this patient group (Ekert et al., 1997; Pike \& Marlow, 2000; Nevalainen et al., 2015). Furthermore, their reliable recording from a preterm infant is technically very challenging in the neonatal intensive care unit environment (Hrbek et al., 1973; Taylor et al., 1996; Smit et al., 2000; Vanhatalo \& Lauronen, 2006).

Studies on both animal (Khazipov et al., 2004; Hanganu et al., 2006; Minlebaev et al., 2007; Colonnese et al., 2010) and human infants (Hrbek et al., 1973; Milh et al., 2007; Vanhatalo et al., 2009) have shown how cortical reaction to sensory stimulation (somatosensory evoked reaction/response, SER) in a preterm brain is substantially different from that of a term infant or an older child. The earliest cortical reactions to sensory stimulation are very large, they take place in the subplate and deeper cortical layers (Wess et al., 2017; Luhmann \& Khazipov, 2018), and they can be readily observed at individual response level in the human neonate (Hrbek et al., 1973; Milh et al., 2007; Vanhatalo et al., 2009). During the preterm period corresponding to the last trimester of pregnancy, these responses will gradually relocate into cortex proper, diminish in size, and eventually become so small that averaging techniques are needed for their detection (Hrbek et al., 1973).

Given the need for objective bedside assessment methods and the now widely available EEG brain monitoring in the neonatal intensive care units, it is intriguing that the salient cortical SERs in the preterm infants have drawn so little attention. As the preterm SERs are readily detectable at a single trial level using conventional EEG monitoring (Vanhatalo et al., 2009), they could even be assessed daily at bedside, and with respect to the evolution of known pathologies, such as IVH, the main risk factor for neurodevelopmental disorders in preterm infants (Sherlock et al., 2005; Patra et al., 2006; Bolisetty et al., 2014; Kidokoro et al., 2014; Twilhaar et al., 2018). Prior studies have shown that IVH may affect spontaneous neuronal network activity (Omidvarnia et al., 2015) as well as subtle properties of spontaneous cortical activity bursts (Cukier et al., 1972; Blume \& Dreyfus-Brisac, 1982; Watanabe et al., 1983; Okumura et al., 2002; Iyer et al., 2015), suggesting 
that functional assessment of cortical circuitry is relevant to further elaborate the impact of structural lesions.

The aim of this study was to systematically characterize the properties of SERs in a cohort of preterm infants. In particular, we wanted to assess the evolution of SERs during prematurity, as well as possible IVH-related changes in preterm SERs.

\section{Materials and Methods}

\section{Participants}

The study group consisted of 29 infants (45 EEG+SER recordings) with a mean post-menstrual age of 30.7 weeks at the time of the EEG and SER recording. The infants were born at a mean gestational age (GA) of 26.3 weeks (23.4-27.9 weeks) and were treated at the neonatal intensive care unit at the Helsinki University Hospital between 2006 and 2008. The EEG and SER data were collected as a part of a larger research project on early brain development and methods development. Other data from this same cohort have been published previously (e.g. Nevalainen et al., 2008; Vanhatalo et al., 2008; Rahkonen et al., 2013; Omidvarnia et al., 2014; Nevalainen et al., 2015; Omidvarnia et al., 2015; Tokariev et al., 2016b; Tokariev et al., 2018). Apart from IVH in eleven infants, the infants were not diagnosed with other brain abnormalities and neither did they receive drug treatments known to affect the SERs studied in this paper.

The study was approved by the Ethics Committee of the Hospital for Children and Adolescents, Helsinki University Hospital, and a written informed consent was obtained from the parents.

Sixteen infants underwent two recordings: first at post-menstrual age of 27-31 weeks, followed by the second recording at post-menstrual age of 30-35 weeks. The other infants had only one recording at post-menstrual age 28-30 weeks (two infants) or at post-menstrual age of 30-35 weeks (eleven infants).

Eleven infants (17 recordings) were diagnosed with either a unilateral (five infants, IVH grades 13) or a bilateral (six infants, IVH grades 2-4 (Papile et al., 1978)) IVH on average 3.3 days after birth. These infants were recorded on average at post-menstrual age of 30.84 weeks (28.0-34.1 weeks), or 5.2 weeks after birth. The delay between IVH diagnosis and EEG+SER recording was 4.7 weeks on average, hence being beyond the acute phase of cortical reaction to IVH (Hayakawa et al., 1997; Okumura et al., 2002). 


\section{EEG and SER recording}

The EEG and SERs were recorded using a NicOne EEG system (Cardinal Healthcare/Natus, USA) and EEG caps with 21 embedded sintered $\mathrm{Ag} / \mathrm{AgCl}$ electrodes (Waveguard, ANT-Neuro, Germany) placed according to the international 10-20 standard, as described earlier (e.g. Vanhatalo et al., 2008; Omidvarnia et al., 2014; Nevalainen et al., 2015). Sampling frequency was $250 \mathrm{~Hz}$ and the recordings were done using a nominal recording bandwidth of 0.016-70 Hz, which was defined by the AC coupling of the amplifier (supposedly $10 \mathrm{~s}$ ) as well as sampling frequency. In addition, disposable $\mathrm{Ag} / \mathrm{AgCl}$ electrodes (Ambu Blue Sensor, Denmark) were used to record electrocardiogram (ECG) and electromyogram (EMG), and respiration was recorded with a chest belt. For a more detailed description of this multichannel newborn EEG recording, see e.g. Vanhatalo et al. (2008), Stjerna et al. (2012), and http://www.helsinki.fi/science/eeg/videos/nemo/.

\section{Tactile stimulation}

The tactile stimuli were applied manually during the EEG recording when the infants were in quiet sleep to be able to apply stimulation during the relative cortical quiescence present during trace alternant/discontinue activity (for a video recording of the procedure, see Stjerna et al. (2012). The infant's palm (right hand (RH), left hand (LH)) or sole of the foot (right foot (RF), left foot (LF)) was repeatedly touched gently using a brush or fingertip, and the timing was recorded in the EEG device using an analog trigger mark based on light or piezoelectric sensor (Vanhatalo et al., 2009; Stjerna et al., 2012). The interstimulus interval varied as the experimenter followed the EEG activity and attempted to give the stimuli preferentially during the low amplitude phase (a.k.a. interburst / inter-spontaneous activity transient (SAT) periods) of quiet sleep. Varying delays between tactile stimulation and the previous spontaneous cortical burst / spontaneous activity transient allowed assessment of refractoriness. To avoid movement, we often used gentle limb fixation by pressing the sleeve against the mattress. A minimum of three successful responses were analysed from each limb. We defined the response as being absent if more than five stimuli were delivered $>3 \mathrm{~s}$ after the latest spontaneous EEG burst, but not a visually detectable EEG responses were seen. With these criteria, all babies showed responses, but because of the complex relationship between spontaneous and evoked activities (Vanhatalo \& Kaila, 2010), we chose not to quantify this in more detail. 


\section{Visual analysis of the SERs}

First, we analysed the signals visually using NicoletOne EEG Reader v5.94.1 (Natus Medical Inc, USA) in Laplacian montage with low-pass filtering at $70 \mathrm{~Hz}$ and notch filter at $50 \mathrm{~Hz}$. We used no additional high-pass filtering to allow inspection of the full waveform (see also Vanhatalo et al. (2009). Only trials with visually detectable responses were selected for further manual analysis. Our careful inspection of synchronized video and analog trigger signals indicated some technical jitter between the trigger signal and the timing of actual stimulus (touch) on the newborn. Hence, we decided not to measure the exact response latencies at millisecond level accuracy, and instead we focused on characterizing the response waveform in more detail (amplitude, duration, and topology).

We measured manually the length and maximum amplitude of the contralateral (cSER) and ipsilateral SER (iSER) after hand stimulus as well as the SER after foot stimulus as presented in Figure 1B. We selected the channel with the largest SER amplitude for further analysis in cases where the response was present in more than one channel. In addition, we manually measured the peak of tactile-stimulation related power increase of 8-20 Hz oscillations during the first second poststimulus using the spectral analysis tool in NicoletOne EEG Reader. For this analysis we included 38 EEG recordings (19 infants), including 14 EEGs from infants with unilateral or bilateral IVH (eight infants). The remaining seven recordings were excluded due to technical issues (e.g. data format) unrelated to patient's clinical course.

We decided to use median values rather than average as the summary metric, because it is less sensitive to outliers that are frequent in smaller physiological datasets of this kind.

We analysed cSERs and iSER separately in those trials where the response was bilateral. First, we wanted to assess relative latencies, or possibly systematic delay between the beginning of the cSER and iSER responses. This assessment was done from recordings from five infants with repeated EEGs (i.e. ten EEGs), bilaterally present responses, and without IVH. We measured the visually observed difference between SERs in contra- and ipsilateral hemisphere, including both the onset of the slow wave as well as the onset of the oscillatory components. These measures were taken from contra- and ipsilateral $\mathrm{C}$ - and $\mathrm{T}$-channels as well as the channel with maximum amplitude response. We only included trials $(n=144)$ where the beginning of response was visually clear in both ipsilateral and the contralateral channel; a high-pass filter at $5 \mathrm{~Hz}$ was used 
for easier identification of the fast component. Finally, median values per recording were computed.

\section{Computational analysis}

All the above analysis is based on visual identification and manual measuring of SERs. This is a common strategy in clinical neurophysiological signal analysis, however it carries a risk of introducing unwanted bias when subjectively selecting the measured waveform properties of interest (see also Palmu et al. (2010)). We therefore wanted to complement our analyses using computational approaches in applicable parts of the work.

To this end, we processed all visually identified tactile stimulations $(\mathrm{n}=2,324)$ using customwritten scripts in the Matlab software. After excluding cases with less than 5 responses per limb, or undefined technical errors in the data conversions, we could run the analysis on altogether 2,087 SERs. The data was read into Matlab from the original EEG signal from $(t=-3$ seconds to $t$ $=+1.5$ seconds relative to the tactile stimulus $(\mathrm{t}=0))$ using Laplacian montage as implemented in NicOne Reader software without additional filtering, apart from the in-built high-pass function of the EEG amplifier.

We calculated the patient average responses at $\mathrm{C} 3, \mathrm{C} 4, \mathrm{~T} 3, \mathrm{~T} 4, \mathrm{P} 3, \mathrm{P} 4, \mathrm{Cz}$ and $\mathrm{Pz}$ channels for each stimulus location (RH, LH, RF, LF) per recording. For each recording, we also calculated median peak values over all stimuli per each limb and channel. Noise was reduced by smoothing with a non-linear median filter, and the maximum amplitude was defined (Figure 1B) from the channels identified as maximal response in the visual analysis (for the hand stimuli, we used $\mathrm{C} 3$, P3, T3, C4, P4, and T4; for the foot stimuli, we used Cz and Pz).

To computationally estimate the total response magnitude, we used root mean square (RMS) in a $500 \mathrm{~ms}$ time window from $200 \mathrm{~ms}$ to $700 \mathrm{~ms}$ after stimulus, as presented in Figure 1B. RMS was computed for all analysed channels (see above), and median was taken to present response of each limb and channel per recording.

We also studied the time-frequency characteristics of the responses by using wavelet transform. We used cwt Matlab function (as it is implemented in MatlabR2016b version) with a Morlet wavelet. First, wavelet transform was computed for each single contralateral response (in C3 for $\mathrm{RH}$ and in $\mathrm{C} 4$ for $\mathrm{LH}$ ) in each infant. Second, we averaged all output wavelet maps for each 
individual. Finally, we averaged individual wavelet maps across groups of interest (based on postmenstrual age).

\section{Statistical analysis}

All results were analysed using Microsoft Excel 2010 or IBM SPSS Statistics 23. Since most data was not normally distributed, we used nonparametric statistical analyses in most occasions. We calculated correlations using Spearman's rank correlation coefficient $\left(\mathrm{r}_{\mathrm{s}}\right)$, and group comparisons using the Mann-Whitney U-test, or the Kruskal-Wallis H-test depending on the number of groups. The onset latency difference between cSER and iSER was tested with Student t-test and null hypothesis $\mathrm{t}($ latency $)=0 \mathrm{~ms}$.

Group comparisons. We analysed SERs first separately for left and right side, as well as for different age groups, followed by pooling when no group differences were observed. The potential effects of IVH on SERs were assessed by forming subgroups from the infants found to present with various forms of IVH, which may occur on either or both sides. We grouped the cohort based on their IVH status on the hemisphere contralateral to the stimulus (Figure 5A). This yielded us four groups: 1) no-IVH infants (no known IVH), 2) unilateral non-lesional IVH (infants with IVH ipsilateral to the stimulus), 3) unilateral lesional IVH (infants with IVH contralateral to the stimulus, i.e. on the side of expected SER), 4) bilateral lesional IVH (infants with bilateral IVH). In this part of the study, we pooled all responses from the left and right hemisphere, and we only grouped them according to the known structural (IVH) lesion.

\section{Comparison between manual and computational analyses}

For an internal validity check, we compared amplitude measures obtained manually vs computationally using custom-scripted routines. These amplitude measures from $\mathrm{C} 3$ or $\mathrm{C} 4$ channels were plotted, and we found them to be highly correlated over a high number of datapoints $\left(r_{s}=0.89(n=2,087)\right.$ with $\left.p<.001\right)$ (see Supporting Information $\left.1 \mathrm{~A}\right)$. The absolute measures obtained with the automatic algorithm were somewhat smaller due to e.g. data smoothing, yet the overall concordance was high enough to allow using them interchangeably. 


\section{Results}

\section{SERs were detected at a high success rate}

The tactile stimulus evoked an expected (Hrbek et al., 1973; Milh et al., 2007; Vanhatalo et al., 2009), consistent, high amplitude and complex response (SER) with a spatial extent over the corresponding primary somatosensory cortex (Figure 1). Stimulation of all limbs evoked at least one visually detectable SER in each recording in all but one infant (no SER after LF stimulus, noIVH group). We also detected relatively often spontaneous activity resembling SERs in the EEGs. In fact, bedside experience and careful comparison of video and EEG records suggest that a significant proportion of these bursting cortical activity transients are related to either infant's spontaneous movements or some external sensory stimulation (see also Vanhatalo \& Kaila (2010)).

After hand stimulation (trial $\mathrm{n}=1,275$ ), a cSER was visually detectable in $95 \%$ of trials (see Figure $2 \mathrm{~A})$ with maximum amplitude at the contralateral $\mathrm{C}$ channel $(60 \%)$ or less often at the contralateral $\mathrm{T}$ or $\mathrm{P}$ channel (35\% and $5 \%$, respectively). The maximum cSER amplitude location differed not only between different recordings, but also, to a lesser degree, between individual stimuli during the same recording. After foot stimulation (trial $n=1,049$ ), a SER was visually detectable in $83 \%$ of trials, with maximum amplitude at $\mathrm{Cz}(84 \%)$ or $\mathrm{Pz}(16 \%)$, consistent with the lower extremity somatosensory representation area.

In addition to the cSER, the stimuli applied to the hands evoked a SER with a comparable waveform on the ipsilateral hemisphere (iSER) in approximately $45 \%$ of the trials showing cSERs (Figure 1C and 2A). An iSER never occurred without a cSER. The majority (70\%) of iSERs had highest amplitude at the temporal (T3 or T4) electrode (Figure 2A). However, both the cSERs and iSERs after hand stimulation were regularly seen at more than one electrode location, while the SER after foot stimulation was more focal at channel $\mathrm{Cz}$.

\section{Stimulus side or preceding brain activity did not affect SER magnitude}

There were no systematic differences between the SERs elicited by right vs left side stimulus (mean amplitude, length, RMS) in the no-IVH group. The SERs were, however, of clearly higher amplitude after hand than foot stimulation $(U=62.000(n=56), p<.001$, Table 1), whereas SER length did not differ between hand and foot stimulations. 
Also the automated computational analysis showed that the magnitude (RMS) of the responses was significantly larger after hand $(\mathrm{C} 3 / \mathrm{C} 4)$ than foot stimuli $(\mathrm{Cz} ; \mathrm{U}=180.000(\mathrm{n}=53), \mathrm{p}=.002)$.

Comparison of the preceding spontaneous brain activity and the subsequent SERs showed that the power of EEG activity during one second preceding stimuli was not related to the response power of the SERs (Supporting Information 2).

\section{cSER magnitude decreases with age}

Correlation analysis including only infants of the no-IVH group showed that the maximum cSER amplitude after hand stimulus decreased with age (Figure 3A) $\left(r_{s}=-0.370(n=28), p=.053\right)$, whereas no apparent change was seen in SER amplitudes associated with foot stimuli $\left(r_{\mathrm{s}}=-0.144\right.$ $(\mathrm{n}=28), \mathrm{p}=.465)$. The duration of SERs increased with age for both hand and foot stimuli (hand: $r_{s}=0.601(n=28), p=.001$, foot: $\left.r_{s}=0.368(n=28), p=.054\right)$.

These findings were supported by the computational analysis, which indicated a significant decrease in RMS with age at the contralateral $\mathrm{C}$ channel after hand stimulation (Figure 3A) ( $\mathrm{r}_{\mathrm{s}}=$ $-0.471(\mathrm{n}=27), \mathrm{p}=.013)$, but no developmental change was seen in the RMS of response to foot stimuli (Cz-channel: $\left.\mathrm{r}_{\mathrm{s}}=-0.168(\mathrm{n}=26), \mathrm{p}=.412\right)$.

\section{Oscillatory activities show differential development}

Visual inspection of the oscillations nested in the SERs suggested that there might be developmental changes over the age range of our cohort. However, the manually measured maximum peak power of the relatively wide $8-20 \mathrm{~Hz}$ frequency band showed no systematic change with age, probably due to high interindividual variability (no-IVH group: hand: $2.7 \pm 1.8$ $\mu \mathrm{V}^{2}$; foot: $1.0 \pm 1.2 \mu \mathrm{V}^{2}$ ) (Figure $\left.3 \mathrm{~A}\right)$.

The frequency spectra of individual SERs suggested that the SER-related oscillations were multifrequency phenomena (Tolonen et al., 2007; Tokariev et al., 2012) where changes may not be captured by the peak power. Therefore, we performed a more thorough time-frequency analysis and found marked developmental changes in the magnitudes of wavelet transform of the oscillations nested on SERs at contralateral C channels (examples shown in Figure 3B). Comparison of three different age groups showed that the peak of higher frequency oscillations $(10-20 \mathrm{~Hz})$ is at the middle of the studied age range, near $\sim 30$ weeks of post-menstrual age, while the amplitude of lower frequency oscillations (5-10 Hz) increased over development (Figure 3B). There was also a temporal difference, with lower frequency oscillations appearing earlier than the 
higher frequency oscillations (Figure 3B). Plotting the time-collapsed amplitudes of different conventional frequency bands (theta $5-8 \mathrm{~Hz}$; alpha $8-13 \mathrm{~Hz}$; beta $13-20 \mathrm{~Hz}$ ) against post-menstrual age showed overall increasing trends (Figure 3C); however, closer inspection of the scatter plots also suggest that the lowest and highest age groups are characterized by lower amplitudes.

\section{iSER amplitude shows less developmental change than cSER}

As the ipsilateral responses were detected so frequently, we wanted to compare the characteristics of ipsilateral and contralateral responses in more detail to determine whether ipsilateral response is a developmentally transient phenomenon. Manual measures of SERs in the no-IVH group showed that when both responses were present, ipsilateral responses were generally lower in amplitude (ipsi:contra ratio $0.77 \pm 0.21)$ (Figure $2 \mathrm{~B})$. On average, the iSER amplitude $(80 \pm 30 \mu \mathrm{V})$ was lower than the cSER amplitude $(97 \pm 26 \mu \mathrm{V})(\mathrm{U}=234.500(\mathrm{n}=56), \mathrm{p}=.010)$. There was, however, a significant developmental decrease in response asymmetry as the cSER amplitudes decreased more rapidly with age (see above) compared with the iSER amplitude, which showed only a weaker developmental trend (no-IVH: $r_{s}=-0.267(n=28), p=.085$, all: $r_{s}=-0.267(n=$ $50), \mathrm{p}=.061$ ); i.e. iSER and cSER amplitudes became more alike with advancing age (Figure 2B). Computational analysis with RMS even showed an age-related increase in the magnitude of iSERs over the temporal areas (T3/T4) (RH (T4): $r_{s}=0.457(n=41), p=.003$, LH $(T 3): r_{s}=0.407(n=$ $40), \mathrm{p}=.009)$, however central locations (C3/C4 channels) showed no correlation with age (Figure $2 \mathrm{C}$, middle).

\section{The iSER onset was delayed compared to the cSER onset}

Comparing timing of different response components indicated a significant delay of iSER compared to the cSER. Both the onset of the iSER slow wave $(63 \pm 48 \mathrm{~ms}$ at the $\mathrm{C}$ channels $(\mathrm{n}=$ $10), p=.003$, and $37 \pm 27 \mathrm{~ms}$ at the maximum response channel $(\mathrm{n}=10), \mathrm{p}=.002)$ and the onset of the iSER fast component (C-channels: $53 \pm 34 \mathrm{~ms}(\mathrm{n}=10), \mathrm{p}=.001$; T-channels: $46 \pm 40 \mathrm{~ms}$ ( $\mathrm{n}$ $=9), \mathrm{p}=.009$; max amplitude channel: $41 \pm 34 \mathrm{~ms}(\mathrm{n}=10), \mathrm{p}=.004)$ were delayed compared to the cSER. 


\section{IVH did not cause significant asymmetries in SER magnitude}

The overall shape of SER in the infants with (IVH) and without IVH (no-IVH) (Figure 4B) appeared to be visually and statistically comparable. No significant differences were found in the amplitudes, RMS measures or topographic SER distributions between infants with and without IVH (all IVH cases pooled together) (Figure 3A). As there was high interindividual variability of response amplitudes, RMS and absolute power in the eleven infants diagnosed with IVH (particularly in the early phases after IVH, i.e. post-menstrual age $<30$ weeks (Figure 4A)), we wanted to examine whether laterality and extent of IVH affected the SER.

We compared SERs in hemispheres affected by IVH ('lesional' and 'unilateral lesional') to SERs in hemispheres contralateral to the unilateral IVH ('non-lesional') and to no-IVH SERs. Figures $4 \mathrm{~A}$ and 5B display the detailed results and statistics. Whereas there were initially (post-menstrual age $<30$ weeks age group) no significant differences between the groups in the amplitude or the RMS of the cSER to hand stimuli or the SER to foot stimuli, there was a change a few weeks later (post-menstrual age $>30$ weeks). After hand stimulus, the cSER amplitudes and RMS at postmenstrual age $>30$ were smaller in the non-lesional group compared to the no-IVH group (Figure 4A). After foot stimulus the amplitude (Figure 5B) and the RMS were smaller in the unilateral IVH group on both the non-lesional (RMS: $U=9.000(n=22), p=.022)$ and lesional hemisphere (RMS: $U=14.000(n=22), p=.061)$ when compared to the no-IVH group. There were, however, no differences between the hemispheres in infants with unilateral IVH, or between infants with bilateral lesion and the no-IVH group.

Spectral analysis of different frequency components within cSER showed no differences between IVH and no-IVH infants in the younger age group ( $<30$ weeks). However, at post-menstrual age $>$ 30 weeks the non-lesional group showed a reduced power at 5-10 Hz and 10-15 Hz frequency bands compared to the no-IVH infants (5-10 and 10-15 Hz: $U=12.000(n=23), p=.035,15-20 \mathrm{~Hz}$ : $\mathrm{U}=14.000(\mathrm{n}=23), \mathrm{p}=.052)$. Again, the group with bilateral lesions did not differ from the noIVH group at any frequency band.

\section{IVH may affect the occurrence of iSER}

Finally, we wanted to assess whether IVH affects iSERs. In the older age group ( $>30$ weeks), the infants with bilateral lesion showed lower incidence of iSERs compared to the no-IVH group ( $29 \%$ vs $55 \%$; $U=15.000(n=25), p=.008)$, whereas no such difference existed at post-menstrual age $<30$ weeks (bilateral IVH 44\% vs no-IVH 38\%). The average rate of bilateral responses 
decreased with age in the infants with bilateral IVH (from $44 \%$ to $29 \%$ ), while the occurrence of iSER increased somewhat in the group of no-IVH infants (from $38 \%$ to $55 \%, r_{s}=0.320(n=28)$, p $=.097$ ). In infants with unilateral IVH, the likelihood of bilateral SERs increased modestly with development when stimulus was applied to the hand ipsilateral to the lesion (from $39 \%$ to $50 \%$ ), but stayed relatively stable when the stimulus was applied on the hand contralateral to the lesion (from 39\% to 41\%). However, the difference between the lesional and non-lesional hemispheres was not significant. IVH did not affect the maximum amplitude of iSER.

\section{Discussion}

Our systematic characterization of SER development in a cohort of human preterm infants shows that SERs can be readily measured and identified from individual trials at bedside, and they show a predictable developmental change during the preterm period. We further show that an IVH may affect the development of SERs with a several weeks delay. The findings are in line with animal experiments (Khazipov et al., 2004; Minlebaev et al., 2007; Luhmann \& Khazipov, 2018), as well as the previous small cohorts showing the SER phenomenon in human neonates (Milh et al., 2007; Vanhatalo et al., 2009). Our work extends this prior knowledge by describing SERs in a much larger cohort. To the best of our knowledge, this work is also the first to disclose a novel mechanism by which frequently encountered structural lesion may become embedded in the later development of the somatosensory system. There are several methodological points that enabled us to detect SERs from single trials with such a high success rate. Prior work has suggested that the occurrence and magnitude of SERs in the immature cortex are affected by the preceding and/or simultaneous cortical activity (Khazipov et al., 2004 ; Milh et al., 2007), and a long refractory period of the infant responses is thought to underlie possible failure or modification in sensory responses when using too short interstimulus intervals (Verley, 1977; Gibson et al., 1992; Araki et al., 1999; Vanhatalo \& Lauronen, 2006). In order to ensure a higher SER occurrence, we used adaptive interstimulus intervals up to several seconds and intended to give the stimuli at periods with minimal EEG background activity. These factors may explain why our computational comparison could not confirm a relationship between SERs and the preceding cortical activity. Furthermore, this apparent discrepancy with prior knowledge from animal studies may result from analytical factors in how the pre-stimulus activity is measured. Prior studies have used visual observations which may be more focused on specific EEG components (e.g. bursting activity), whereas our automated quantitative measures are by and large ignorant of the underlying 
physiological mechanisms. Further studies are needed to systematically characterize the effects of interstimulus interval and prestimulus activity on the slowest 'carrier wave' component of the SER. In clinical settings, the success rate and reliability of SERs can be improved by using long enough (seconds) interstimulus interval and selecting SERs with only limited background activity (see also Stjerna et al. (2012).

\section{Origin of preterm SERs}

The SERs to hand and foot stimuli showed an expected scalp topography that roughly corresponded to the respective areas of the somatosensory cortex. In accordance with the previous literature, the SERs were very large, consisting of a slow wave and an overlying oscillatory component (Hrbek et al., 1973; Milh et al., 2007; Vanhatalo et al., 2009; Vanhatalo \& Lauronen, 2006). The corresponding cortical reaction in the rodent models is often called spinde burst (reviewed in Luhmann \& Khazipov (2018)). Prior experimental work on rodent models has indicated a key role of subplate in SER generation, and changes in subplate-cortical interaction likely reflect on the developmental characteristics of SERs (Luhmann \& Khazipov, 2018; Luhmann et al., 2018). For instance, subplate ablation will abolish both endogenous and sensory evoked spindle burst activity (Tolner et al., 2012), and subplate neurons are reactive to sensory stimuli before other the reaction becomes visible in cortical neurons (Wess et al., 2017). Subplate neuronal networks provide hence a relay between thalamus and cortex, and the subplate neurons allow coordination of cortical network ensambles, which is believed to provide key guidance for early cortical organization (Luhmann et al., 2018). Our time frequency-analysis indicated differential development of higher and lower frequency oscillations at around the time when the main invasion of thalamo-cortical innervation is known to take place in the human (Kostovic \& Judas, 2010; Molnar et al., 2019). It is easy to envision that the observed changes, a developmental decline in higher frequency and an increase in lower frequency, may reflect the changing subplate-cortex interaction (Kostovic \& Judas, 2010) which is well characterized in the rodent models (Luhmann \& Khazipov, 2018). There is a translational bottleneck, however, coming from the different oscillatory frequency ranges. The oscillations in the rodent models are typically at much higher frequencies compared to the human infant recordings. Some of the difference may arise from the very different recording conditions. All human research is based on scalp EEG, while most of animal experiments use intraparenchymal microelectrodes or fluorometric dies to 
observe activities in larger neuronal ensambles in vitro and in vivo. It is well known that higher frequency activities attenuate in scalp EEG recorings due to spatial smearing (a.k.a.volume conduction), however the exact animal model equivalents to our present human work remain to be shown from comparable non-invasive animal recordings.

\section{Ipsilateral response}

In addition to the contralateral SER to hand stimulation, we also detected a systematic albeit smaller ipsilateral response (iSER), confirming the prior work of Hrbek et al., 1973. Our extensive theoretical and empiric studies on newborn EEG signals (Odabaee et al., 2013; Odabaee et al., 2014; Gargiulo et al., 2015; Tokariev et al., 2016a), including works on conventional evoked potentials (Nevalainen et al., 2017) in term infants, have shown that newborn scalp EEG signal is spatially very specific. Hence, the present results cannot be explained by spatial smearing of cortical signals akin to what is commonly seen in the adult scalp EEG studies. In other words, the present findings of cSER and iSER indicate that preterm cortex exhibits a genuinely bilateral response.

Our findings show a delay of iSER compared to cSER, which supports the assumption that iSER is triggered by contralateral hemisphere via interhemispheric relays rather than by a direct ipsilateral thalamo-cortical connection. While there is no data showing direct thalamocortical ipsilateral responses, a recent experimental work suggests that ipsilateral responses exist in the primary somatosensory cortex in a rodent model where they appear to be under callosally mediated control from the contralateral hemisphere (Marcano-Reik \& Blumberg, 2008). A spatial spread of early SERs is well documented in the experimental models, where cortical responses (a.k.a. spindle burst in rodents) are shown to occur via networks both within the subplate and cortex proper (Tolner et al., 2012; Inacio et al., 2016; McVea et al., 2016; Luhmann \& Khazipov, 2018).

Recent experimental findings have demonstrated distinct developmental changes in the cortical processing of afferent information (Bernhard et al., 1967; Luhmann \& Khazipov, 2018), while prior human work has suggested significant developmental changes in the early responses of multiple sensory modalities (Ellingson, 1960; Ellingson, 1964; Hrbek \& Mareš, 1964; Hrbek et al., 1973; Kaminska et al., 2018; Whitehead et al., 2019). In our study, we observed an expected decline in cSER amplitudes, however we also found a perhaps unexpected lack of comparable 
change in the iSERs. The early life responses are shown in the primary somatosensory cortex in both hemispheres (Marcano-Reik \& Blumberg, 2008), while ipsilateral responses in adults primarily originate in the secondary or higher somatosensory cortices (Del Vecchio et al., 2018). These findings together are compatible with the idea that the prominent ipsilateral responses in the preterm primary sensory cortices are a developmentally transient phenomenon during the period when organization of the sensory-motor cortical networks is guided by sensory input (Inacio et al., 2016). The immature, bursting-type sensory responses akin to SERs are known to arise from a complex network involving subplate-cortex structures, they disappear after the age comparable to human neonatal period (Chipaux et al., 2013; Kaminska et al., 2018; Luhmann \& Khazipov, 2018) and they will be replaced by the adult-like intracortical responses (for a schematic drawing, see Vanhatalo \& Lauronen (2006). Hence, though we cannot pinpoint the exact cortical area generating the prominent iSERs observed in our study, we suggest that they represent organization of the bilateral sensory-motor cortical networks, a phenomenon specific for the preterm period. Future studies should assess the evolution of these responses beyond the age groups included in the present study, to bring further insight to their developmental significance.

\section{Perinatal IVH shows a delayed effect on somatosensory development}

Perinatal IVH with associated parenchymal injury may affect the thalamo-cortical somatosensory pathways and is a known risk factor for later developing $\mathrm{CP}$, including sensori-motor dysfunctions. Hence, we expected to find a robust effect of IVH on the SERs immediately after injury. However, we could not see group differences in the first recordings, i.e. with an average delay of 3.1 weeks after IVH diagnosis, and the effects only became measurable in recordings several weeks the later (average delay 6.2 weeks). Even then, the effects of IVH on SERs were surprisingly small (possibly due to mostly low grade IVHs in our cohort), with smaller amplitudes in infants with unilateral IVH and a lower iSER occurrence in infants with bilateral IVH. Analysis of real human data is by nature challenged by the lack of control of the insults, as well as limited numbers of infants available for such studies. Yet, the present findings support an idea that IVH is not a transient phenomenon, but it is embedded in the later neurodevelopment (Dell'Anna et al., 1997; Morales et al., 2011; Vaiserman \& Koliada, 2017).

The slow wave component of the SERs and the faster oscillatory responses are assumed to originate from distinct cortical and subplate structures (Luhmann \& Khazipov, 2018). In the context of explaining injury-related reactions, an important role is assigned to the subplate, which 
functions as a key relay network, but it is also particularly vulnerable to exogenous challenges. A cerebrovascular damage, such as IVH, affecting the subplate could result in impaired development of these networks as experimentally shown in animal models (Ghosh et al., 1990; Kanold et al., 2003; Tolner et al., 2012). Such effects would not necessarily be instant, but they could become apparent after a delay, during which the networks responsible for the given (SER) response reorganize. Our results imply that at least part of the damage after IVH is not instant but is formed gradually during brain development.

\section{Could tactile SERs add value to conventional SEPS at neonatal intensive care units?}

Conventional SEP paradigm assumes that preterm SEPs behave closely akin to the adult responses, but the current literature has not shown convincing evidence for much practical utility of conventional SEPs at preterm age. Shifting clinical focus from the early N1 components to the full SER response could improve their clinical utility since it presumably reflects functions of the developmentally transient subplate structure, known for its extreme sensitivity to hypoxia (Albrecht et al., 2005). Notably, prior experimental animal work has indicated that this slow SER component is sensitive to asphyxia (Meyerson, 1968), supporting together with our findings the notion that tactile SERs might offer a clinically useful early bedside measure of sensorimotor network function. Such measure is particularly needed for guiding early therapeutic interventions (Finch-Edmondson et al., 2019).

To be able to catch the full preterm response, the recording and stimulation paradigms have to account for the well-known variability, time scales and longer refractory periods in preterm SERs (Vanhatalo \& Lauronen, 2006). In addition to the already discussed long interstimulus interval and selective stimulation during low voltage EEG activity of quiet sleep, the stimulation type may also play a role. Tactile stimuli are both more physiological and easier to perform compared to the conventional electrical SEPs, making them readily available at neonatal intensive care unit bedside. Visual evaluation of tactile SERs is fast and easy from the raw EEG data even when using a limited monitoring setup with fewer electrodes (Vanhatalo et al., 2009). Our results also show that visual SER analysis is highly comparable to the computational approach, hence supporting visual analysis for common bedside use. The relatively high variability of SERs, however, prompts future studies to define its optimal clinical use. For example, studies should define whether clinical utility comes from quantified analyses of discrete SER components, or 
maybe from coarser indicators, such as dichotomic presence/absence of any visually identified SER.

In conclusion, the present work emphasizes the need to search for new neurobiologically based and clinically practical methods to better fit the special characteristics of the preterm brain function. We show that tactile stimulation of a preterm infant evokes robust cortical responses that are both easy to perform and quick to analyse. They offer functional insight to the subplate-cortex network, which is unachievable with the current SEP methods based on electrical stimulation of the peripheral nerve.

\section{Acknowledgements}

Our sincere thanks go to the EEG technicians of the Department of Clinical Neurophysiology in Children's Hospital for conducting the EEG and SER measurements. We also thank the personnel of the Neonatal Intensive Care Unit at the Children's Hospital of Helsinki University Hospital for seamless co-operation. This work was supported by the Helsinki University Hospital Funds [1C27012974], Academy of Finland [253130], Lastentautien Tutkimussäätiö, and Juselius Foundation. The sponsors were not involved in the collection, analysis and interpretation of data or in the writing of the manuscript.

\section{Competing Interests}

None of the authors have potential conflicts of interest to be disclosed.

\section{Author Contributions}

Susanna Leikos analysed and interpreted the data and drafted the manuscript.

Anton Tokariev performed the time-frequency analysis and revised the manuscript

Ninah Koolen performed computational analysis and its interpretation and revised the manuscript.

Päivi Nevalainen interpreted the data and revised the manuscript.

Sampsa Vanhatalo designed and conceptualized the study, interpreted the data and revised the manuscript. 


\section{Data Accessibility}

Raw EEG files (which include the SERs) supporting the findings of this study are available from the corresponding author (S.L.) upon reasonable request and approval by the ethics boards of the corresponding institutions.

This article is protected by copyright. All rights reserved 


\section{Abbreviations}

cSER, contralateral SER

EEG, electroencephalography

HIE, hypoxic-ischaemic encephalopathy

$\mathrm{IVH}$, intraventricular haemorrhage

iSER, ipsilateral SER

LF, left foot

LH, left hand

$\mathrm{RF}$, right foot

$\mathrm{RH}$, right hand

RMS, root mean square

SER, somatosensory evoked response

SEP, somatosensory evoked potential

This article is protected by copyright. All rights reserved 


\section{References}

Albrecht, J., Hanganu, I.L., Heck, N. \& Luhmann, H.J. (2005) Oxygen and glucose deprivation induces major dysfunction in the somatosensory cortex of the newborn rat. Eur J Neurosci, 22, 2295-2305.

Araki, A., Takada, A., Yasuhara, A. \& Kobayashi, Y. (1999) The effects of stimulus rates on the amplitude of median nerve somatosensory evoked potentials: The developmental change. Brain Dev, 21, 118-121.

Bernhard, C.G., Kolmodin, G.M. \& Meyerson, B.A. (1967) On the prenatal development of function and structure in the somesthetic cortex of the sheep. Prog Brain Res, 26, 60-77.

Blume, W.T. \& Dreyfus-Brisac, C. (1982) Positive rolandic sharp waves in neonatal EEG; types and significance. Electroencephalogr Clin Neurophysiol, 53, 277-282.

Bolisetty, S., Dhawan, A., Abdel-Latif, M., Bajuk, B., Stack, J., Lui, K. \& New South Wales and Australian Capital Territory Neonatal Intensive Care Units' Data Collection (2014) Intraventricular hemorrhage and neurodevelopmental outcomes in extreme preterm infants. Pediatrics, 133, 55-62.

Chipaux, M., Colonnese, M.T., Mauguen, A., Fellous, L., Mokhtari, M., Lezcano, O., Milh, M., Dulac, O., Chiron, C., Khazipov, R. \& Kaminska, A. (2013) Auditory stimuli mimicking ambient sounds drive temporal "delta-brushes" in premature infants. PLoS One, 8, e79028.

Colonnese, M.T., Kaminska, A., Minlebaev, M., Milh, M., Bloem, B., Lescure, S., Moriette, G., Chiron, C., Ben-Ari, Y. \& Khazipov, R. (2010) A conserved switch in sensory processing prepares developing neocortex for vision. Neuron, 67, 480-498.

Cukier, F., Andre, M., Monod, N. \& Dreyfus-Brisac, C. (1972) Contribution of EEG to the diagnosis of intraventricular hemorrhages in the premature infant. Rev Electroencephalogr Neurophysiol Clin, 2, 318-322. 
Del Vecchio, M., Caruana, F., Sartori, I., Pelliccia, V., Lo Russo, G., Rizzolatti, G. \& Avanzini, P. (2018) Ipsilateral somatosensory responses in humans: The tonic activity of SII and posterior insular cortex. Brain Struct Funct, 224, 9-18.

Dell'Anna, E., Chen, Y., Engidawork, E., Andersson, K., Lubec, G., Luthman, J. \& HerreraMarschitz, M. (1997) Delayed neuronal death following perinatal asphyxia in rat. Exp Brain Res, 115, 105-115.

Desmedt, J.E., Brunko, E. \& Debecker, J. (1976) Maturation of the somatosensory evoked potentials in normal infants and children, with special reference to the early N1 component. Electroencephalogr Clin Neurophysiol, 40, 43-58.

Ekert, P.G., Taylor, M.J., Keenan, N.K., Boulton, J.E. \& Whyte, H.E. (1997) Early somatosensory evoked potentials in preterm infants: Their prognostic utility. Biol Neonate, 71, 83-91.

Ellingson, R.J. (1960) Cortical electrical responses to visual stimulation in the human infant. Electroencephalogr Clin Neurophysiol, 12, 663-677.

Ellingson,R.J. (1964) Studies of the electrical activity of the developing human brain. Prog Brain Res, 9, 26-53.

Finch-Edmondson, M., Morgan, C., Hunt, R.W. \& Novak, I. (2019) Emergent prophylactic, reparative and restorative brain interventions for infants born preterm with cerebral palsy. Front Physiol, 10, 15.

Gargiulo, P., Belfiore, P., Friethgeirsson, E.A., Vanhatalo, S. \& Ramon, C. (2015) The effect of fontanel on scalp EEG potentials in the neonate. Clin Neurophysiol, 126, 1703-1710.

Ghosh, A., Antonini, A., McConnell, S.K. \& Shatz, C.J. (1990) Requirement for subplate neurons in the formation of thalamocortical connections. Nature, 347, 179-181.

Gibson, N.A., Brezinova, V. \& Levene, M.I. (1992) Somatosensory evoked potentials in the term newborn. Electroencephalogr Clin Neurophysiol, 84, 26-31. 
Hanganu, I.L., Ben-Ari, Y.\& Khazipov, R. (2006) Retinal waves trigger spindle bursts in the neonatal rat visual cortex. J Neurosci, 26, 6728-6736.

Hayakawa, F., Okumura, A., Kato, T., Kuno, K. \& Watanabe, K. (1997) Disorganized patterns: Chronic-stage EEG abnormality of the late neonatal period following severely depressed EEG activities in early preterm infants. Neuropediatrics, 28, 272-275.

Hrbek, A. \& Mareš, P. (1964) Cortical evoked responses to visual stimulation in full-term and premature newborns. Electroencephalogr Clin Neurophysiol, 16, 575-581.

Hrbek, A., Karlberg, P. \& Olsson, T. (1973) Development of visual and somatosensory evoked responses in pre-term newborn infants. Electroencephalogr Clin Neurophysiol, 34, 225-232.

Inacio, A.R., Nasretdinov, A., Lebedeva, J. \& Khazipov, R. (2016) Sensory feedback synchronizes motor and sensory neuronal networks in the neonatal rat spinal cord. Nat Commun, 7, 13060.

Iyer, K.K., Roberts, J.A., Hellstrom-Westas, L., Wikstrom, S., Hansen Pupp, I., Ley, D., Breakspear, M. \& Vanhatalo, S. (2015) Early detection of preterm intraventricular hemorrhage from clinical electroencephalography. Crit Care Med, 43, 2219-2227.

Johnson, S. \& Marlow, N. (2017) Early and long-term outcome of infants born extremely preterm. Arch Dis Child, 102, 97-102.

Kaminska, A., Delattre, V., Laschet, J., Dubois, J., Labidurie, M., Duval, A., Manresa, A., Magny, J.F., Hovhannisyan, S., Mokhtari, M., Ouss, L., Boissel, A., Hertz-Pannier, L., Sintsov, M., Minlebaev, M., Khazipov, R. \& Chiron, C. (2018) Cortical auditory-evoked responses in preterm neonates: Revisited by spectral and temporal analyses. Cereb Cortex, 28, 3429-3444.

Kanold, P.O., Kara, P., Reid, R.C. \& Shatz, C.J. (2003) Role of subplate neurons in functional maturation of visual cortical columns. Science, 301, 521-525.

Karniski, W., Wyble, L., Lease, L. \& Blair, R.C. (1992) The late somatosensory evoked potential in premature and term infants. II. topography and latency development. Electroencephalogr Clin Neurophysiol, 84, 44-54. 
Khazipov, R., Sirota, A., Leinekugel, X., Holmes, G.L., Ben-Ari, Y. \& Buzsaki, G. (2004) Early motor activity drives spindle bursts in the developing somatosensory cortex. Nature, 432, 758-761.

Kidokoro, H., Anderson, P.J., Doyle, L.W., Woodward, L.J., Neil, J.J. \& Inder, T.E. (2014) Brain injury and altered brain growth in preterm infants: Predictors and prognosis. Pediatrics, 134, e44453.

Kontio, T., Toet, M.C., Hellstrom-Westas, L., van Handel, M., Groenendaal, F., Stjerna, S., Vanhatalo, S. \& de Vries, L.S. (2013) Early neurophysiology and MRI in predicting neurological outcome at 9-10 years after birth asphyxia. Clin Neurophysiol, 124, 1089-1094.

Kostovic, I. \& Judas, M. (2010) The development of the subplate and thalamocortical connections in the human foetal brain. Acta Paediatr, 99, 1119-1127.

Laureau, E. \& Marlot, D. (1990) Somatosensory evoked potentials after median and tibial nerve stimulation in healthy newborns. Electroencephalogr Clin Neurophysiol, 76, 453-458.

Luhmann, H.J. \& Khazipov, R. (2018) Neuronal activity patterns in the developing barrel cortex. Neuroscience, 368, 256-267.

Luhmann, H.J., Kirischuk, S. \& Kilb, W. (2018) The superior function of the subplate in early neocortical development. Front Neuroanat, 12, 97.

Majnemer, A. \& Rosenblatt, B. (1996) Evoked potentials as predictors of outcome in neonatal intensive care unit survivors: Review of the literature. Pediatr Neurol, 14, 189-195.

Marcano-Reik, A.J. \& Blumberg, M.S. (2008) The corpus callosum modulates spindle-burst activity within homotopic regions of somatosensory cortex in newborn rats. Eur J Neurosci, 28, 1457-1466.

Marlow, N., Wolke, D., Bracewell, M.A., Samara, M. \& EPICure Study Group (2005) Neurologic and developmental disability at six years of age after extremely preterm birth. $N$ Engl J Med, 352, 9-19. 
McVea, D.A., Murphy, T.H. \& Mohajerani, M.H. (2016) Large scale cortical functional networks associated with slow-wave and spindle-burst-related spontaneous activity. Front Neural Circuits, 10, 103.

Meyerson, B.A. (1968) Ontogeny of interhemispheric functions. an electrophysiological study in pre- and postnatal sheep. Acta Physiol Scand Suppl, 312, 1-111.

Milh, M., Kaminska, A., Huon, C., Lapillonne, A., Ben-Ari, Y. \& Khazipov, R. (2007) Rapid cortical oscillations and early motor activity in premature human neonate. Cereb Cortex, 17, 15821594.

Minlebaev, M., Ben-Ari, Y.\& Khazipov, R. (2007) Network mechanisms of spindle-burst oscillations in the neonatal rat barrel cortex in vivo. J Neurophysiol, 97, 692-700.

Molnar, Z., Clowry, G.J., Sestan, N., Alzu'bi, A., Bakken, T., Hevner, R.F., Huppi, P.S., Kostovic, I., Rakic, P., Anton, E.S., Edwards, D., Garcez, P., Hoerder-Suabedissen, A. \& Kriegstein, A. (2019) New insights into the development of the human cerebral cortex. $J$ Anat, 235, 432-451.

Morales, P., Bustamante, D., Espina-Marchant, P., Neira-Pena, T., Gutierrez-Hernandez, M.A., Allende-Castro, C. \& Rojas-Mancilla, E. (2011) Pathophysiology of perinatal asphyxia: Can we predict and improve individual outcomes? Epma J, 2, 211-230.

Mwaniki, M.K., Atieno, M., Lawn, J.E. \& Newton, C.R. (2012) Long-term neurodevelopmental outcomes after intrauterine and neonatal insults: A systematic review. Lancet, 379, 445-452.

Nevalainen, P., Rahkonen, P., Pihko, E., Lano, A., Vanhatalo, S., Andersson, S., Autti, T., Valanne, L., Metsaranta, M. \& Lauronen, L. (2015) Evaluation of somatosensory cortical processing in extremely preterm infants at term with MEG and EEG. Clin Neurophysiol, 126, 275283.

Nevalainen, P., Pihko, E., Metsäranta, M., Andersson, S., Autti, T. \& Lauronen, L. (2008) Does very premature birth affect the functioning of the somatosensory cortex? - A magnetoencephalography study. Int J Psychophysiol, 68, 85-93. 
Nevalainen, P., Marchi, V., Metsaranta, M., Lonnqvist, T., Toiviainen-Salo, S., Vanhatalo, S. \& Lauronen, L. (2017) Evoked potentials recorded during routine EEG predict outcome after perinatal asphyxia. Clin Neurophysiol, 128, 1337-1343.

Nevalainen, P., Marchi, V., Metsaranta, M., Lonnqvist, T., Vanhatalo, S. \& Lauronen, L. (2018) Evaluation of SEPs in asphyxiated newborns using a 4-electrode aEEG brain monitoring set-up. Clin Neurophysiol Pract, 3, 122-126.

Odabaee, M., Freeman, W.J., Colditz, P.B., Ramon, C. \& Vanhatalo, S. (2013) Spatial patterning of the neonatal EEG suggests a need for a high number of electrodes. Neuroimage, 68, 229-235.

Odabaee, M., Tokariev, A., Layeghy, S., Mesbah, M., Colditz, P.B., Ramon, C. \& Vanhatalo, S. (2014) Neonatal EEG at scalp is focal and implies high skull conductivity in realistic neonatal head models. Neuroimage, 96, 73-80.

Okumura, A., Hayakawa, F., Kato, T., Kuno, K. \& Watanabe, K. (2002) Developmental outcome and types of chronic-stage EEG abnormalities in preterm infants. Dev Med Child Neurol, 44, 729734.

Omidvarnia, A., Fransson, P., Metsaranta, M. \& Vanhatalo, S. (2014) Functional bimodality in the brain networks of preterm and term human newborns. Cereb Cortex, 24, 2657-2668.

Omidvarnia, A., Metsaranta, M., Lano, A. \& Vanhatalo, S. (2015) Structural damage in early preterm brain changes the electric resting state networks. Neuroimage, 120, 266-273.

Palmu, K., Wikstrom, S., Hippelainen, E., Boylan, G., Hellstrom-Westas, L. \& Vanhatalo, S. (2010) Detection of 'EEG bursts' in the early preterm EEG: Visual vs. automated detection. Clin Neurophysiol, 121, 1015-1022.

Papile, L.A., Burstein, J., Burstein, R. \& Koffler, H. (1978) Incidence and evolution of subependymal and intraventricular hemorrhage: A study of infants with birth weights less than 1,500 gm. J Pediatr, 92, 529-534. 
Patra, K., Wilson-Costello, D., Taylor, H.G., Mercuri-Minich, N. \& Hack, M. (2006) Grades I-II intraventricular hemorrhage in extremely low birth weight infants: Effects on neurodevelopment. $J$ Pediatr, 149, 169-173.

Pihko, E., Lauronen, L., Wikstrom, H., Taulu, S., Nurminen, J., Kivitie-Kallio, S. \& Okada, Y. (2004) Somatosensory evoked potentials and magnetic fields elicited by tactile stimulation of the hand during active and quiet sleep in newborns. Clin Neurophysiol, 115, 448-455.

Pike, A.A., Marlow, N. \& Dawson, C. (1997) Posterior tibial somatosensory evoked potentials in very preterm infants. Early Hum Dev, 47, 71-84.

Pike, A.A. \& Marlow, N. (2000) The role of cortical evoked responses in predicting neuromotor outcome in very preterm infants. Early Human Development, 57, 123-135.

Pisani, F. \& Spagnoli, C. (2016) Monitoring of newborns at high risk for brain injury. Ital J Pediatr, 42, 48.

Rahkonen, P., Nevalainen, P., Lauronen, L., Pihko, E., Lano, A., Vanhatalo, S., Pesonen, A.K., Heinonen, K., Raikkonen, K., Valanne, L., Autti, T., Andersson, S. \& Metsaranta, M. (2013) Cortical somatosensory processing measured by magnetoencephalography predicts neurodevelopment in extremely low-gestational-age infants. Pediatr Res, 73, 763-771.

Saigal, S. \& Doyle, L.W. (2008) An overview of mortality and sequelae of preterm birth from infancy to adulthood. Lancet, 371, 261-269.

Scalais, E., Francois-Adant, A., Nuttin, C., Bachy, A. \& Guerit, J.M. (1998) Multimodality evoked potentials as a prognostic tool in term asphyxiated newborns. Electroencephalogr Clin Neurophysiol, 108, 199-207.

Sherlock, R.L., Anderson, P.J., Doyle, L.W. \& Victorian Infant Collaborative Study Group (2005) Neurodevelopmental sequelae of intraventricular haemorrhage at 8 years of age in a regional cohort of ELBW/very preterm infants. Early Hum Dev, 81, 909-916.

Smit, B.J., Ongerboer de Visser, B.W., de Vries, L.S., Dekker, F.W. \& Kok, J.H. (2000) Somatosensory evoked potentials in very preterm infants. Clin Neurophysiol, 111, 901-908. 
Stjerna, S., Voipio, J., Metsaranta, M., Kaila, K. \& Vanhatalo, S. (2012) Preterm EEG: A multimodal neurophysiological protocol. J Vis Exp, 60, e3774.

Suppiej, A., Cappellari, A., Franzoi, M., Traverso, A., Ermani, M. \& Zanardo, V. (2010) Bilateral loss of cortical somatosensory evoked potential at birth predicts cerebral palsy in term and nearterm newborns. Early Hum Dev, 86, 93-98.

Suppiej, A., Cappellari, A., Talenti, G., Cainelli, E., Di Capua, M., Janes, A., Longo, D., Mardari, R., Marinaccio, C., Pro, S., Sciortino, P., Trevisanuto, D., Vittorini, R. \& Manara, R. (2018) Bilateral loss of cortical SEPs predict severe MRI lesions in neonatal hypoxic ischemic encephalopathy treated with hypothermia. Clin Neurophysiol, 129, 95-100.

Swarte, R.M., Cherian, P.J., Lequin, M., Visser, G.H. \& Govaert, P. (2012) Somatosensory evoked potentials are of additional prognostic value in certain patterns of brain injury in term birth asphyxia. Clin Neurophysiol, 123, 1631-1638.

Taylor, M.J., Boor, R. \& Ekert, P.G. (1996) Preterm maturation of the somatosensory evoked potential. Electroencephalogr Clin Neurophysiol, 100, 448-452.

Tokariev, A., Palmu, K., Lano, A., Metsaranta, M. \& Vanhatalo, S. (2012) Phase synchrony in the early preterm EEG: Development of methods for estimating synchrony in both oscillations and events. Neuroimage, 60, 1562-1573.

Tokariev, A., Vanhatalo, S. \& Palva, J.M. (2016a) Analysis of infant cortical synchrony is constrained by the number of recording electrodes and the recording montage. Clin Neurophysiol, 127, 310-323.

Tokariev, A., Videman, M., Palva, J.M. \& Vanhatalo, S. (2016b) Functional brain connectivity develops rapidly around term age and changes between vigilance states in the human newborn. Cereb Cortex, 26, 4540-4550.

Tokariev, A., Stjerna, S., Lano, A., Metsaranta, M., Palva, J.M. \& Vanhatalo, S. (2018) Preterm birth changes networks of newborn cortical activity. Cereb Cortex, 29, 1697. 
Tolner, E.A., Sheikh, A., Yukin, A.Y., Kaila, K. \& Kanold, P.O. (2012) Subplate neurons promote spindle bursts and thalamocortical patterning in the neonatal rat somatosensory cortex. $J$ Neurosci, 32, 692-702.

Tolonen, M., Palva, J.M., Andersson, S. \& Vanhatalo, S. (2007) Development of the spontaneous activity transients and ongoing cortical activity in human preterm babies. Neuroscience, 145, $997-$ 1006.

Tombini, M., Pasqualetti, P., Rizzo, C., Zappasodi, F., Dinatale, A., Seminara, M., Ercolani, M., Rossini, P.M. \& Agostino, R. (2009) Extrauterine maturation of somatosensory pathways in preterm infants: A somatosensory evoked potential study. Clin Neurophysiol, 120, 783-789.

Twilhaar, E.S., Wade, R.M., de Kieviet, J.F., van Goudoever, J.B., van Elburg, R.M. \& Oosterlaan, J. (2018) Cognitive outcomes of children born extremely or very preterm since the 1990s and associated risk factors: A meta-analysis and meta-regression. JAMA Pediatr, 172, 361367.

Vaiserman, A.M. \& Koliada, A.K. (2017) Early-life adversity and long-term neurobehavioral outcomes: Epigenome as a bridge? Hum Genomics, 11, 34.

Vanhatalo, S. \& Lauronen, L. (2006) Neonatal SEP - back to bedside with basic science. Semin Fetal Neonatal Med, 11, 464-470.

Vanhatalo, S., Metsaranta, M. \& Andersson, S. (2008) High-fidelity recording of brain activity in the extremely preterm babies: Feasibility study in the incubator. Clin Neurophysiol, 119, 439-445.

Vanhatalo, S., Jousmaki, V., Andersson, S. \& Metsaranta, M. (2009) An easy and practical method for routine, bedside testing of somatosensory systems in extremely low birth weight infants. Pediatr Res, 66, 710-713.

Vanhatalo, S. \& Kaila, K. (2010) Spontaneous and evoked activity in the early human brain. In Lagercrantz, H., Hanson, M.A., Ment, L.R. \& Peebles, D.M. (eds), The newborn brain:

Neuroscience \& clinical applications. Cambridge University Press, United Kingdom, pp. 229-244. 
Verley, R. (1977) The post-natal development of the functional relationships between the thalamus and the cerebral cortex in rats and rabbits. Electroencephalogr Clin Neurophysiol, 43, 679-690.

Watanabe, K., Hakamada, S., Kuroyanagi, M., Yamazaki, T. \& Takeuchi, T. (1983)

Electroencephalographic study of intraventricular hemorrhage in the preterm newborn.

Neuropediatrics, 14, 225-230.

Wess, J.M., Isaiah, A., Watkins, P.V. \& Kanold, P.O. (2017) Subplate neurons are the first cortical neurons to respond to sensory stimuli. Proc Natl Acad Sci U S A, 114, 12602-12607.

Whitehead, K., Papadelis, C., Laudiano-Dray, M.P., Meek, J. \& Fabrizi, L. (2019) The emergence of hierarchical somatosensory processing in late prematurity. Cereb Cortex, 29, 2245-2260.

Willis, J., Seales, D. \& Frazier, E. (1984) Short latency somatosensory evoked potentials in infants. Electroencephalogr Clin Neurophysiol, 59, 366-373.

Willis, J., Duncan, C. \& Bell, R. (1987) Short-latency somatosensory evoked potentials in perinatal asphyxia. Pediatr Neurol, 3, 203-207. 


\section{Tables}

Table 1. Average response length, maximum amplitude and RMS in the no-IVH group.

\begin{tabular}{|l|l|l|}
\hline & Hand & Foot \\
\hline Length, manual $[\mathrm{ms}]$ & $942 \pm 123$ & $1099 \pm 181$ \\
\hline Max amplitude, manual $[\mu \mathrm{V}]^{* * *}$ & $97 \pm 26$ & $53 \pm 15$ \\
\hline RMS, computational $[\mu \mathrm{V}]^{* *}$ & $33 \pm 17$ & $19 \pm 8.0$ \\
\hline
\end{tabular}

$$
* \mathrm{p}<.05, * * \mathrm{p}<.01, * * * \mathrm{p}
$$

$<.001$ 
A

Example of SER after left hand (LH) stimulus

LH stim LH stim

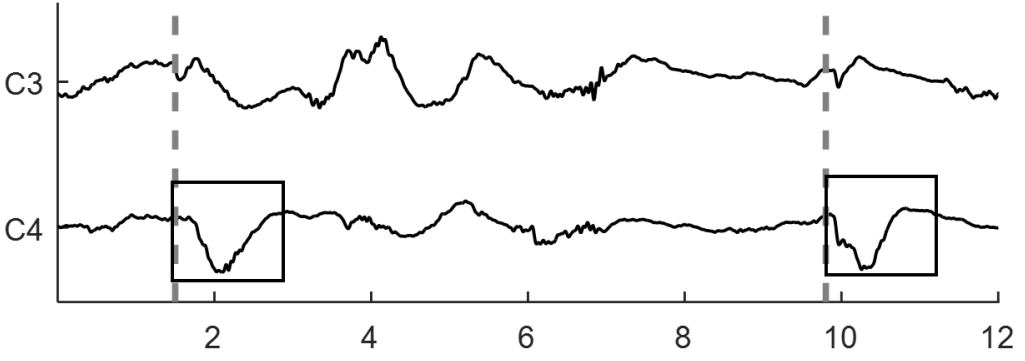

Example of SER after left foot (LF) stimulus

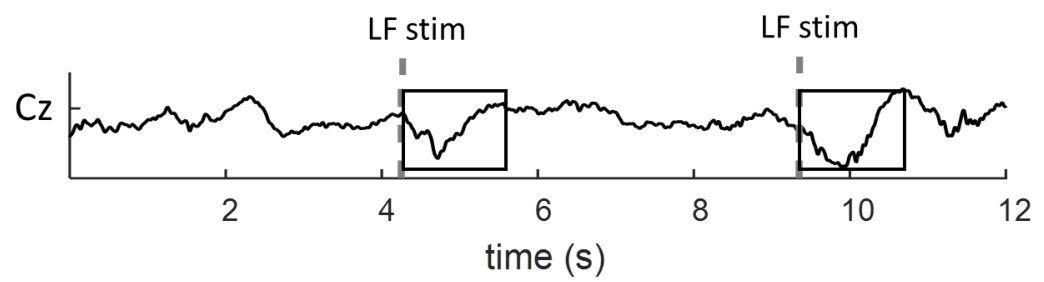

c
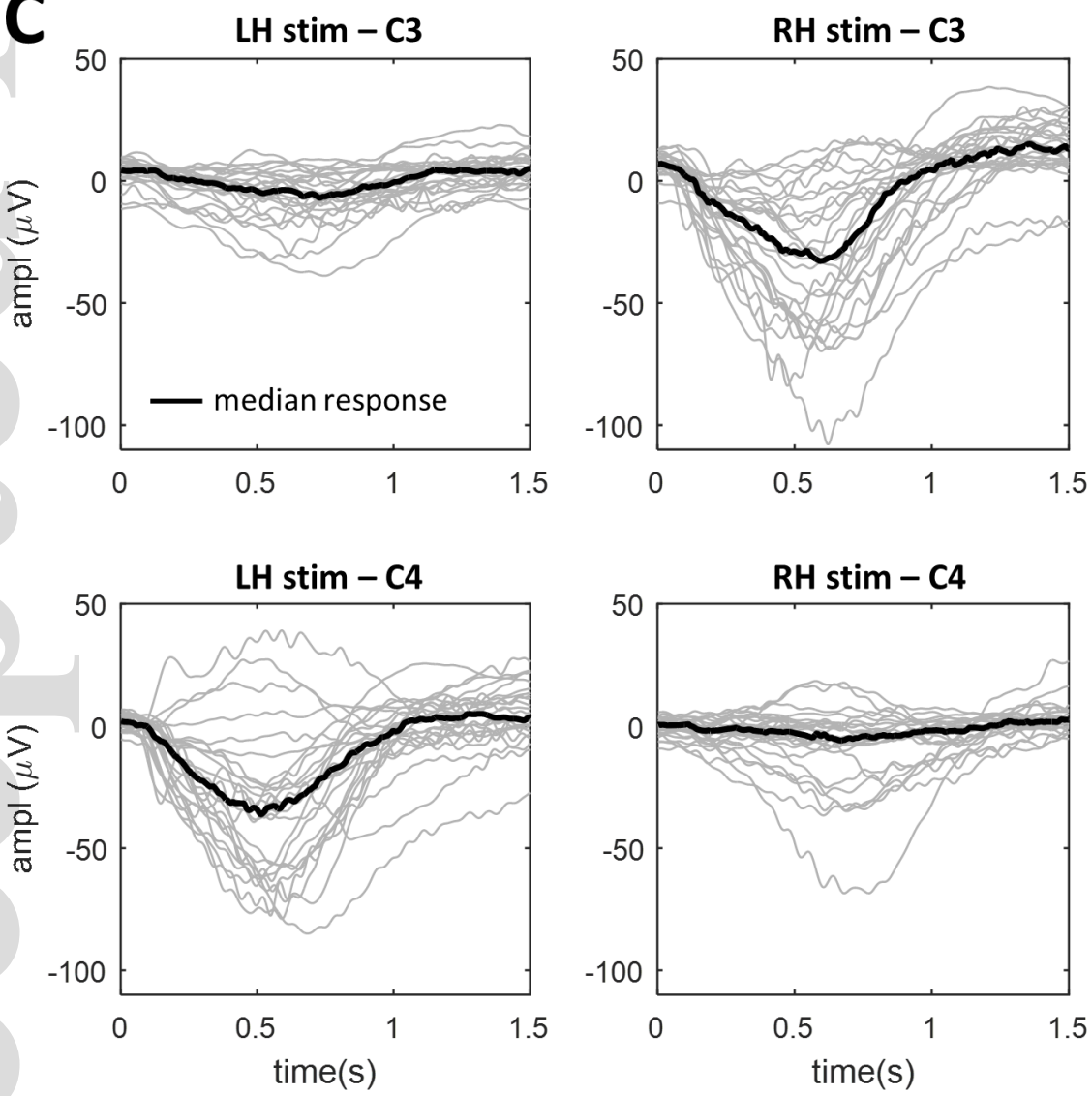

ejn_14613_f1.tif
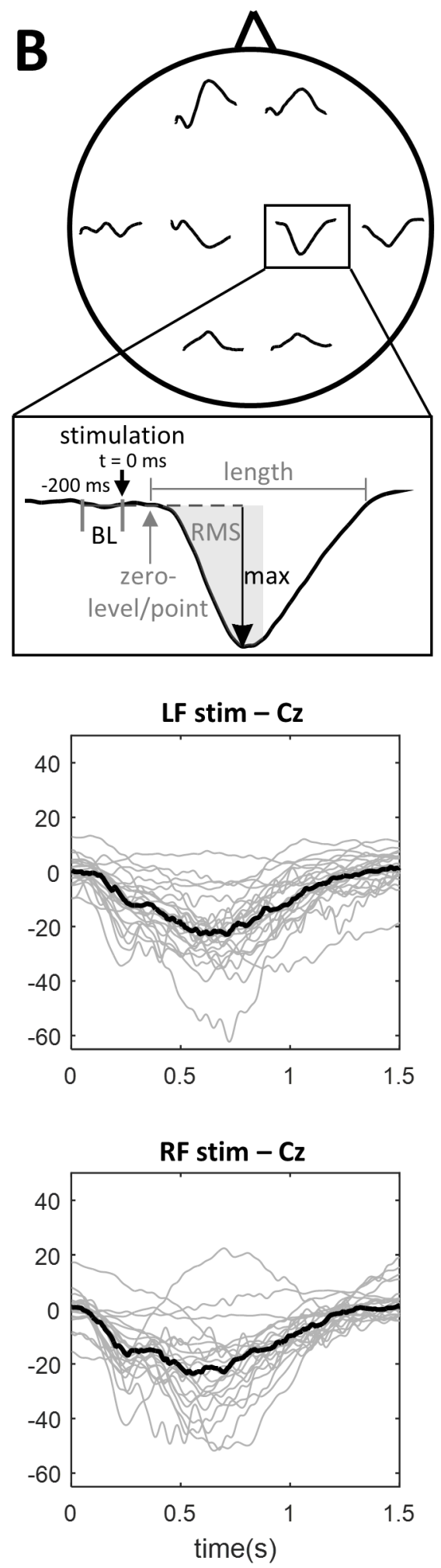

This article is protected by copyright. All rights reserved 
A

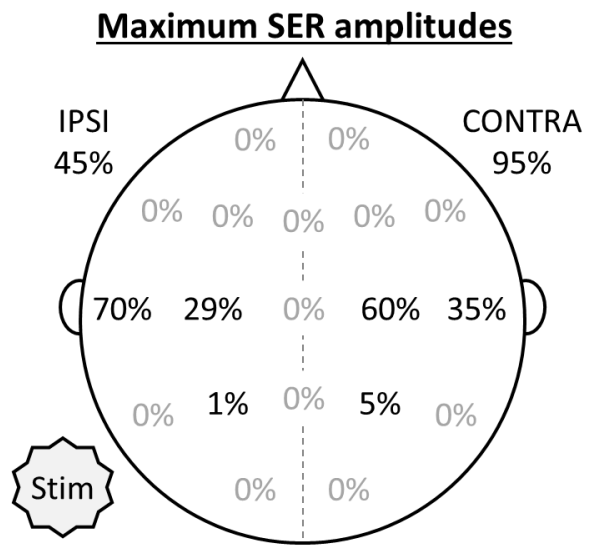

C

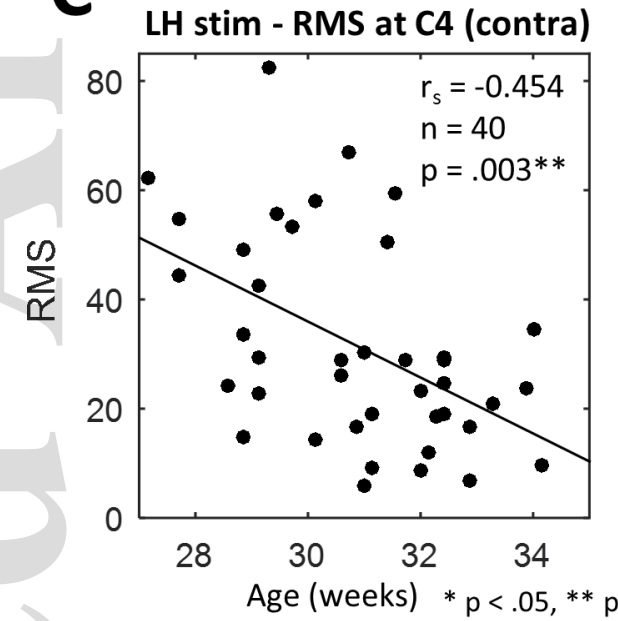

\section{ra)}

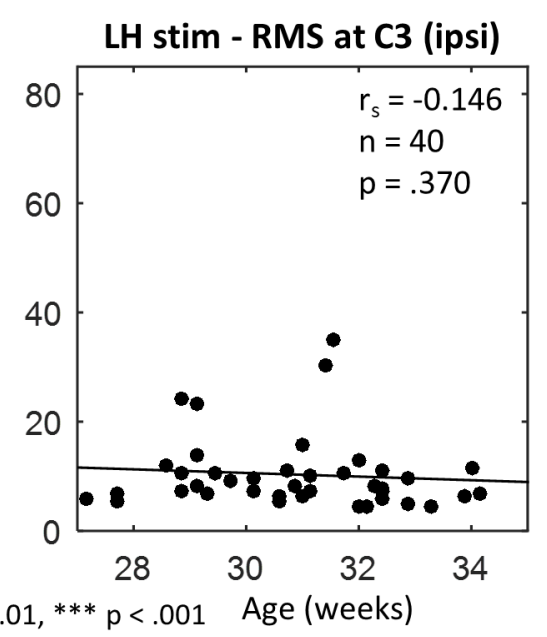

ejn_14613_f2.tif
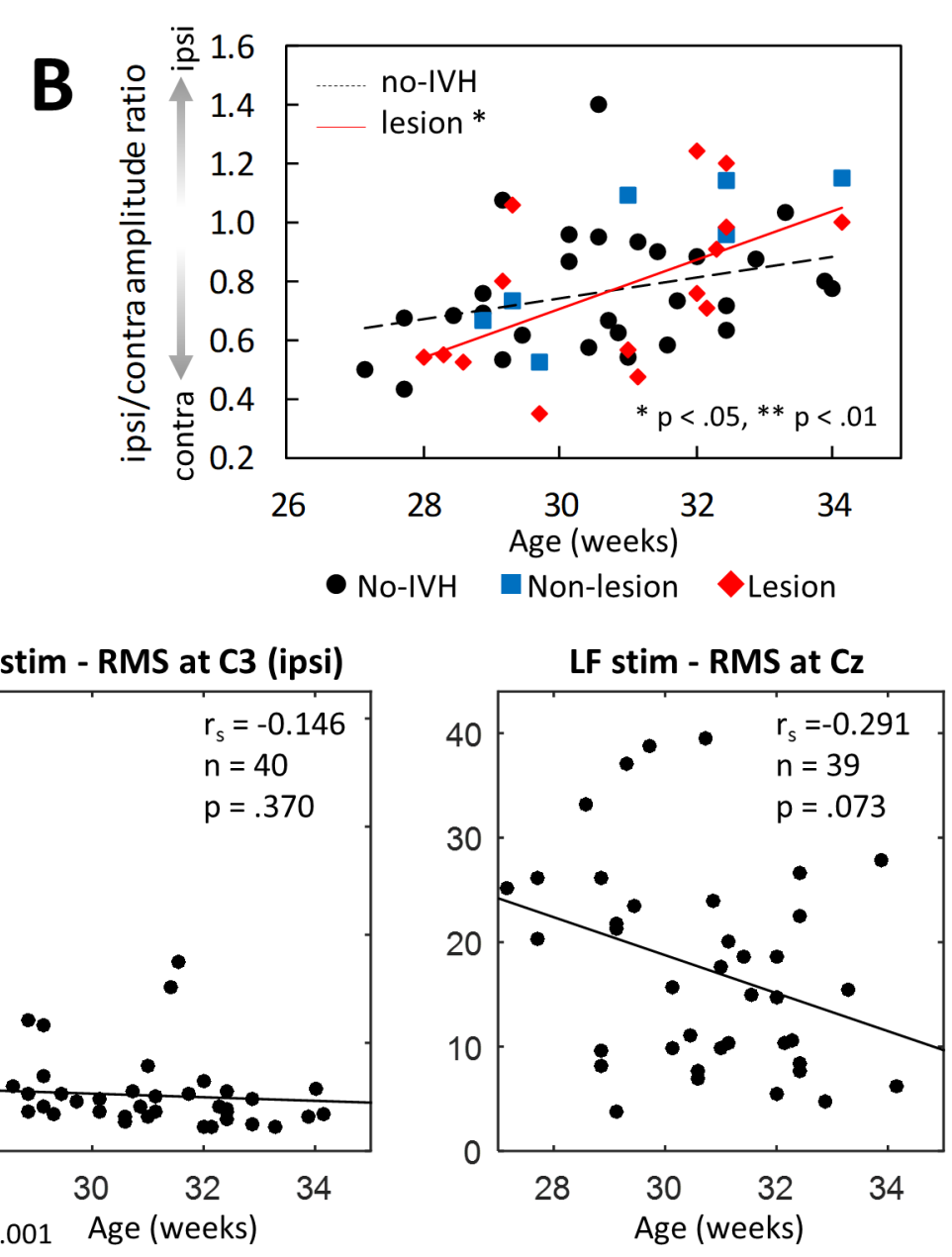

This article is protected by copyright. All rights reserved 

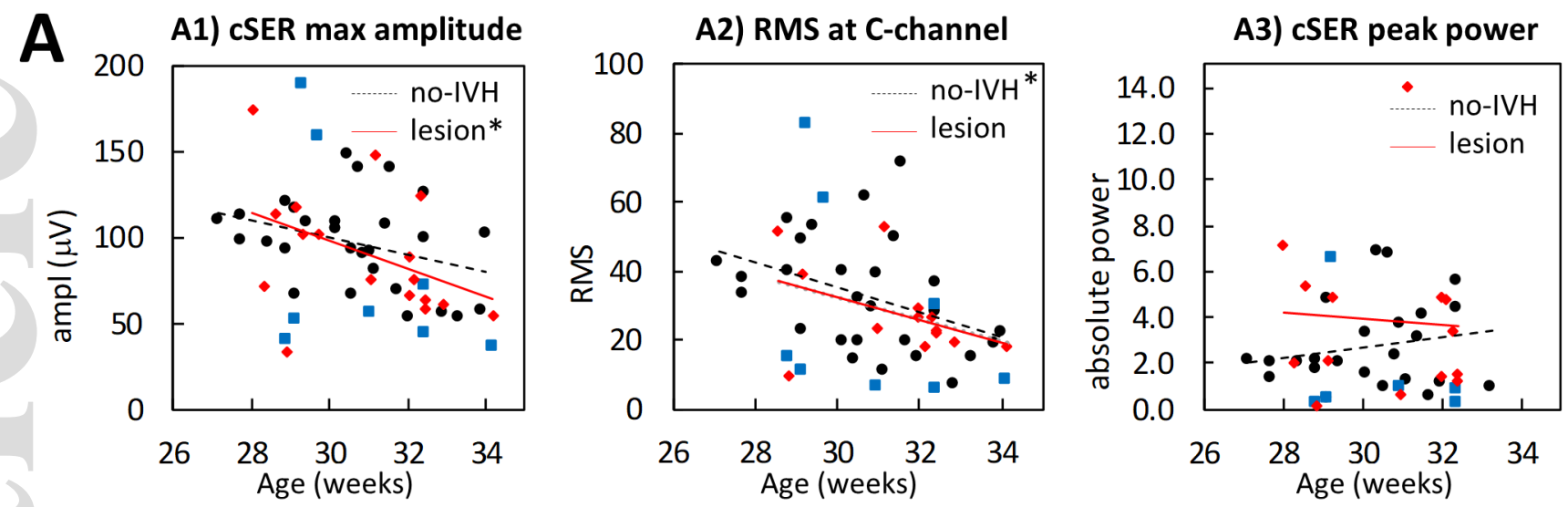

- No-IVH Non-lesion Lesion $* p<.05,{ }^{* *} p<.01$

\section{B}
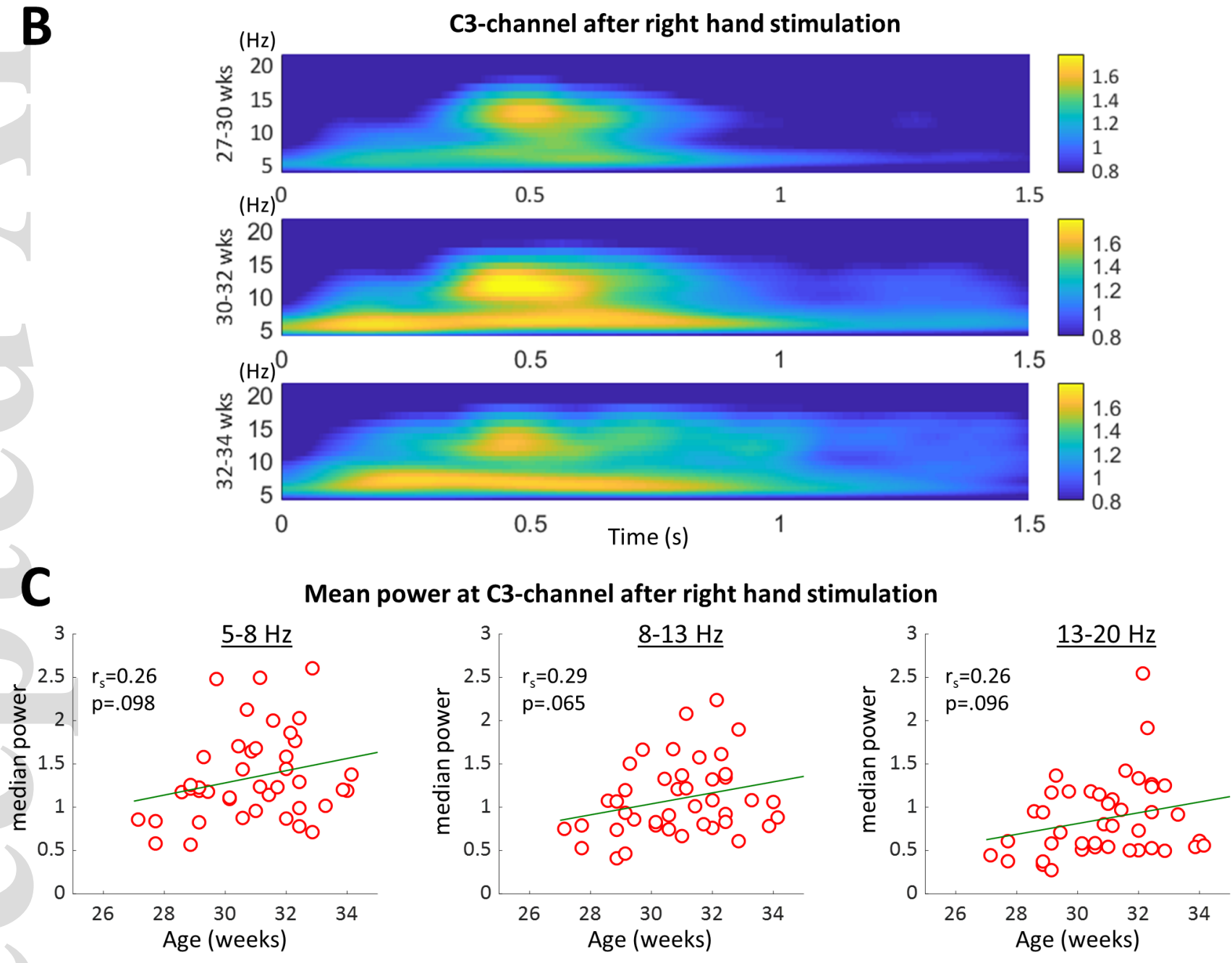

ejn_14613_f3.tif 

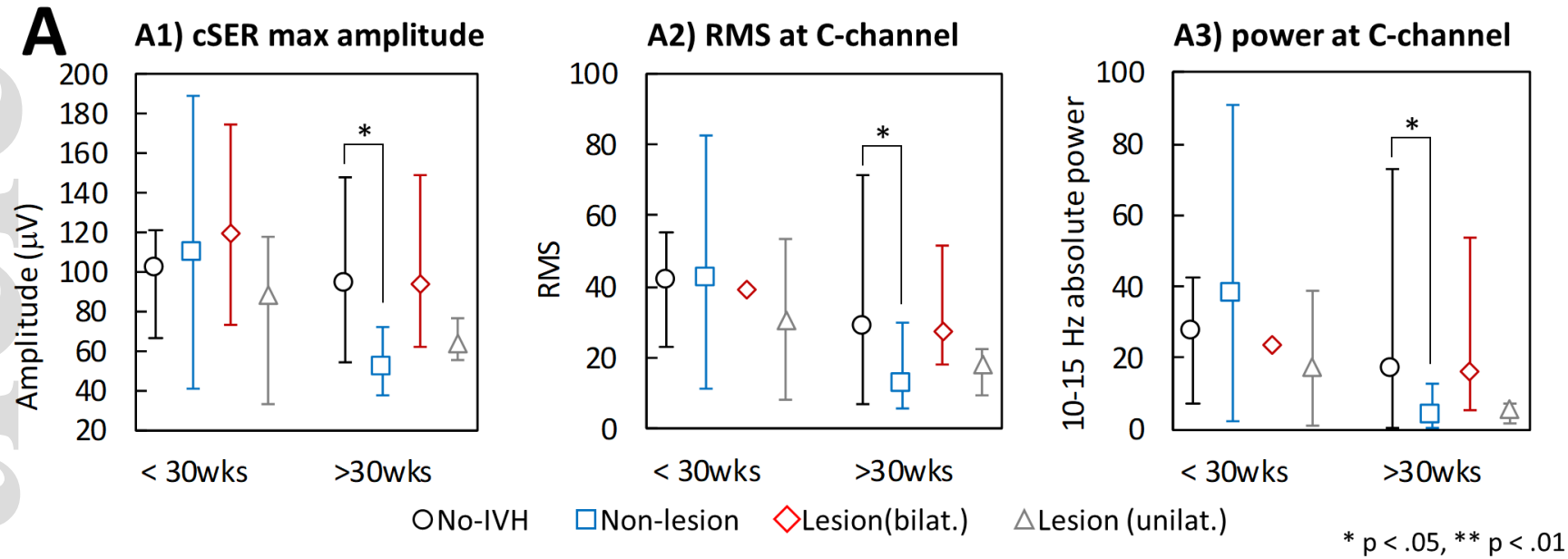

B

No-IVH and IVH children SERs
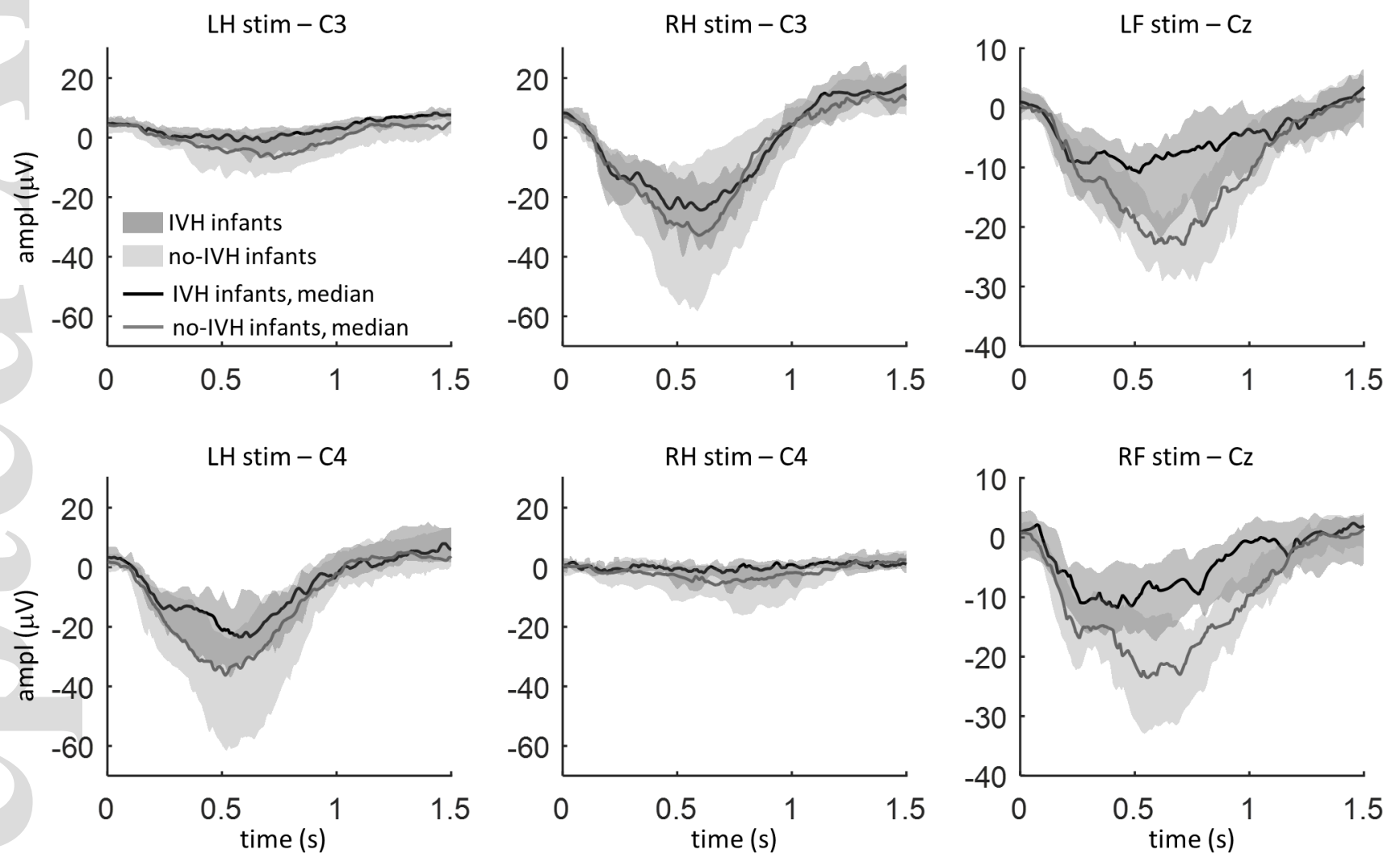

ejn_14613_f4.tif

This article is protected by copyright. All rights reserved 
A
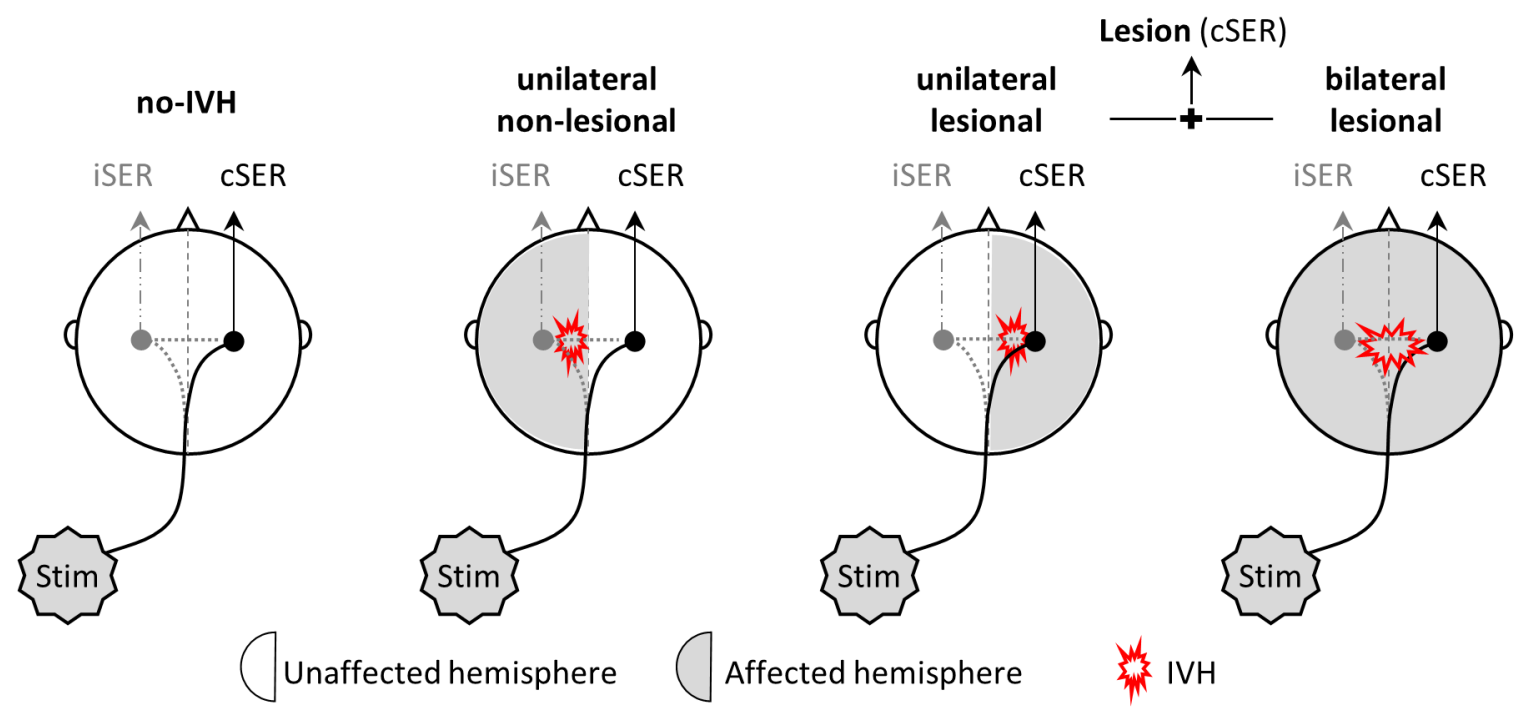

B

\section{$\underline{\text { SER development compared to the no-IVH group }}$}

\begin{tabular}{|c|c|c|}
\hline ר & no & VH \\
\hline & & \\
\hline & $<30 \mathrm{wks}$ & $>30 \mathrm{wks}$ \\
\hline ER ampl & & \\
\hline iSER ampl & & \\
\hline iSER-\% & $38 \%$ & $55 \%$ \\
\hline $\begin{array}{l}\text { SER ampl } \\
\text { foot stim) }\end{array}$ & & \\
\hline
\end{tabular}
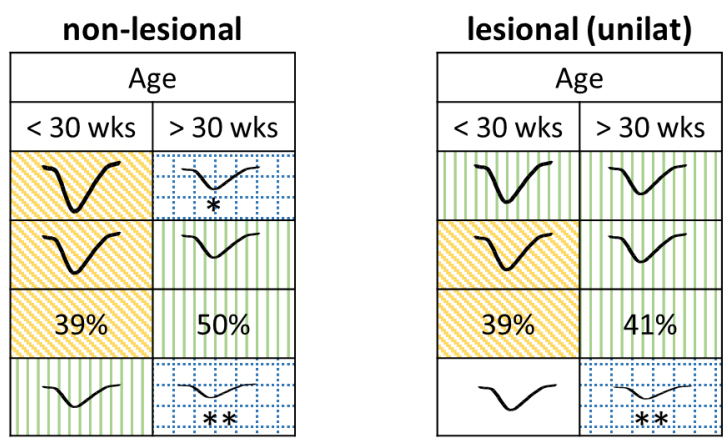

lesional (bilat)

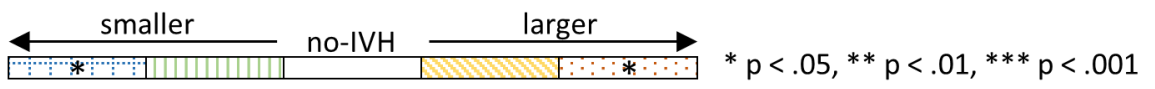

ejn_14613_f5.tif 